\title{
Research and Practice of Lean Management of Coal Firing in Thermal Power Plants
}

\author{
Jun Tao Xia * \\ SDIC Qinzhou Electric Power Co.,Ltd., Qinzhou, 535008,China \\ xjtgtqz@163.com
}

\section{Keywords: Thermal power plants; Coal; Costs; Lean management; Upgrading}

\begin{abstract}
China has abundant coal resources. Majority of China's electricity comes from coal plants, and the pattern will not change in the short term. However, the pollution from coal plants is still a huge issue. Energy conservation and environmental protection, the coal market and the electricity market have become three major challenges in thermal power plant. Power generation cost is dominated by coal, so coal management is an important subject. A large coal-fired power plant has seized the favorable opportunity to take the initiative to deal with the situation. The plant hired an outside management consulting company to perfect the management systems, and to develop energy-saving emission reduction strategy. Especially in the fuel management, they carried out benchmarking and lean management in the whole process of production, and the employees were mobilized to upgrade equipments and systems. After five years the company has achieved remarkable results. This paper mainly introduces upgrading of coal handling system, the optimized setting of management departments, improvement of field measurement equipments, coal blending and construction of information management platform. These make the whole process of power generation more efficient, and can be used for reference of similar power company, in order to improve the management level.
\end{abstract}

\section{Introduction}

By far the most common fuel for power generation is coal. In the thermal power plant, the chemical energy of the fuel into electricity, coal accounts for 70-80\% of total cost. In the face of the fierce market competition and increasingly stringent environmental regulations, the thermal power enterprises put a lot of work in the external marketing and internal control, especially in the fuel management. Effects of the past few decades in planned economy still ingrained. It is difficult to completely eradicate in the short term [1]. There are widespread problems such as weak market awareness, unreasonable division, lack of investment of equipment, poor personnel quality and imperfect information [2]. In the past five years a large coal-fired power plant has seized opportunities to strengthen all staff's sense of crisis and sense of innovation, and carried out benchmarking and lean management of coal in Guangxi, China. So that is why coal consumption for supplying fell more than 6 grams. In 2014 the company was awarded the Guangxi energy-saving emission reduction achievement award, and the national energy management system certification. The core competitiveness of enterprise has greatly improved.

\section{System Overview}

The thermal power plant is located in the coastal area. The total generation capacity of $3320 \mathrm{MW}$ is built in two phases. Plasma ignition and combustion stabilization technology is adopted. It is so advanced that most of the fuel is cheap imported coal, and it dose't need diesel anymore. In the first phase two units of $600 \mathrm{MW}$ were built whose coal handling system was designed for four units of 630MW. When two units of 1000MW were built in the second phase, the coal handling system was upgraded to improve the speed of belt with a small increase in equipment and facilities for two units of 630MW and two units of 1030MW. A lot of land and investment were saved. The system has A, B two 
belt channels. As Figure 1 shows, the technological process consists of four ship unloaders in the dock, four bucket-wheel stacker reclaimers in the coal yard, electronic belt scale, on-line coal analyzer, and automatic sampling device.

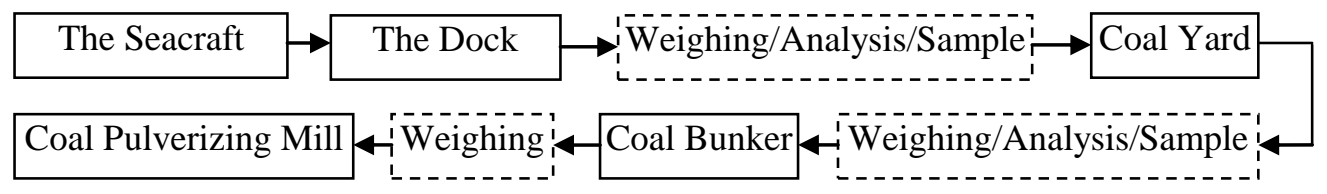

Fig. 1 Diagram of Process of Coal Handling System

\section{Optimized Setting of Departments}

In order to rationalize the model, the fuel management department was especially established to take over the operation of coal transportation system from the power generation department, and appliance repair from the equipment maintenance department. The production technology department took over the coal quality analysis from the power generation department, and coalpile inventorying from the operating department. At the same time the company promoted more able workers to key positions. Such the power generation department can focus on doing a good job of coal blending work, and the business management department can focus on more effective regulation and supervision [3]. The division of the departments before and after the adjustment is in table 1 below.

Table 1 Division of the departments before and after the adjustment

\begin{tabular}{|c|c|c|c|c|c|c|c|c|c|c|}
\hline \multirow{2}{*}{ Departments } & $\begin{array}{c}\text { Generation } \\
\text { Dept. }\end{array}$ & \multicolumn{2}{c|}{$\begin{array}{c}\text { Maintenance } \\
\text { Dept. }\end{array}$} & \multicolumn{2}{c|}{$\begin{array}{c}\text { Fuel } \\
\text { Dept. }\end{array}$} & \multicolumn{2}{c|}{$\begin{array}{c}\text { Technology } \\
\text { Dept. }\end{array}$} & \multicolumn{3}{c|}{$\begin{array}{c}\text { Operating } \\
\text { Dept. }\end{array}$} \\
\hline & Before & After & Before & After & Before & After & Before & After & Before & After \\
\hline System operation & $\sqrt{ }$ & & & & & $\sqrt{ }$ & & & & \\
\hline System Maintenance & & & $\sqrt{ }$ & & & $\sqrt{ }$ & & & & \\
\hline Coal quality analysis & $\sqrt{ }$ & & & & & & & $\sqrt{ }$ & & \\
\hline Coalpile inventorying & & & & & & & & $\sqrt{ }$ & $\sqrt{ }$ & \\
\hline Coal blending & $\sqrt{ }$ & $\sqrt{ }$ & & & & & & & & \\
\hline Supervision & & & & & & & $\sqrt{ }$ & & $\sqrt{ }$ & $\sqrt{ }$ \\
\hline
\end{tabular}

\section{Main Devices on Site}

Electronic Belt Scale. The design accuracy of two scales for coal into the plant and two scales for coal into the furnace was $0.5 \%$. Because of the higher failure rate and the larger measuring deviation the economy of coal blending was seriously affected. The plant oganized manufacturers to upgrade and develop higher reliability, higher precision electronic belt scale. The transformation was so successful that the accuracy of $0.25 \%$ became a reality. The project had made a big profit on less investment. In 2014 the plant obtained the patent of double channels structure in electronic belt scale [4], as shown in Figure 2.

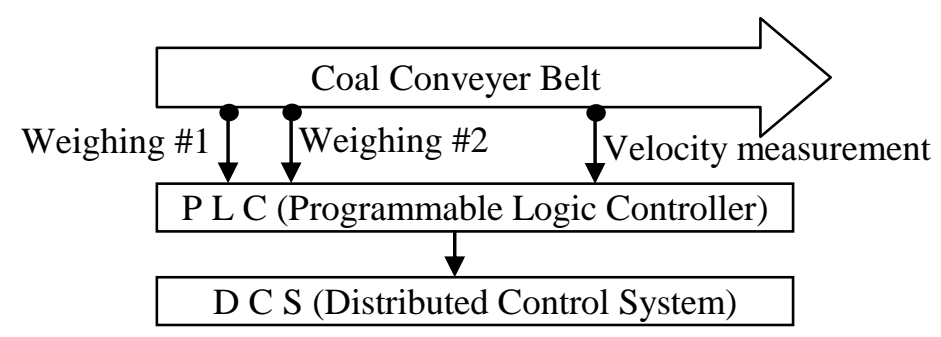

Fig. 2 Diagram of Double Channels Structure 
Automatic Sampling and Intelligent Packaging System. An automatic sampling device was for two belts before so that the representation of coal samples was poor, which made it unsuited to lean management. Through revamping, a belt was installed with a set of automatic sampling device, and two sets could substitute for each other. Equipment utilization rate and the representation of coal samples were both improved obviously. In addition, the intelligent packaging system was added that could avoid man-made disturbance, water loss and other unfavorable factors [5]. The system uses control technology of the internet of things, and the network topology is shown in figure 3.

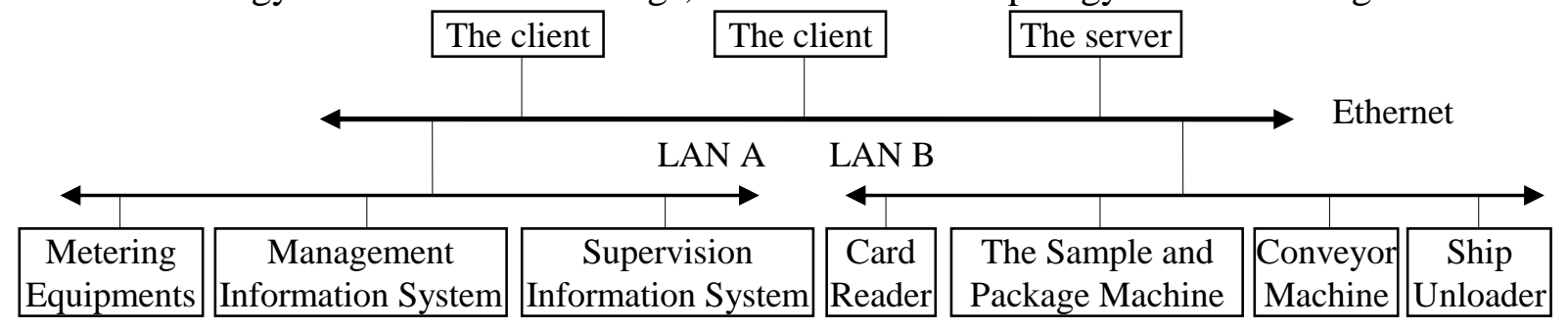

Fig. 3 Diagram of the Network Topology

Online Measuring Equipments. Coal quality, inventory and consumption are the basic data of lean management, and every single one of them is needed. The external marketing and internal combustion optimization are based on them [6]. Quantification management can become a reality by measuring equipment online, for example, the system of coal quality analysis online, coal consumption online and coal inventory online by laser.

The system of coal quality analysis online provides real-time parameters for quality acceptance and business of settlement, also guides the management of coal yard, coal blending and combustion adjustment.

In accordance with "Technical Specifications of Coal Consumption Online Monitoring of the Thermal Power Plants in Southern Power Grid ", the system of coal consumption was built for energy saving scheduling and optimization of operation of units. The system is shown in Figure 4.

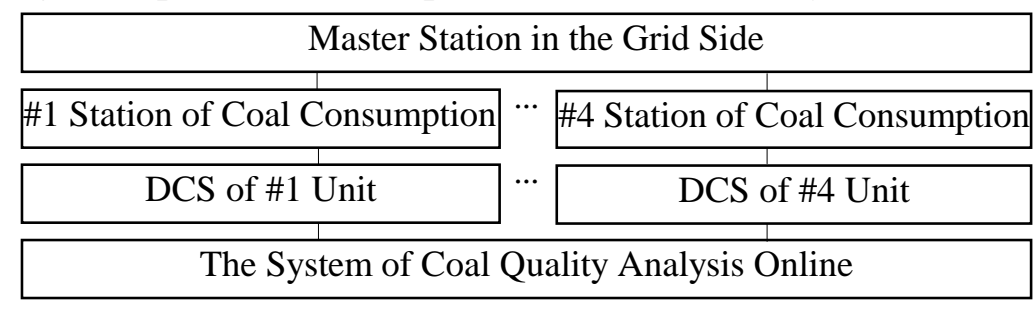

Fig. 4 Diagram of the system of Coal Consumption Online

The laser probes are arranged on the bucket-wheel stacker reclaimers, and continuously scan the coal pile. The software platform calculates coal inventory by the positioning and laser measurement technology [7]. The principle of measuring is shown in Figure 5.

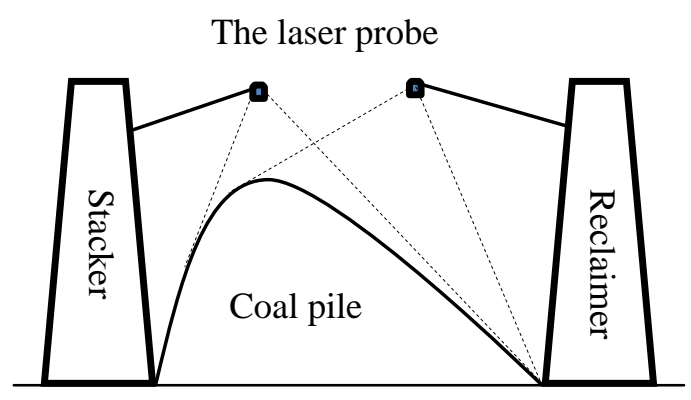

Fig. 5 Diagram of coal inventory online 


\section{Information Management Platform}

At present the intensive management of the fuel system is the general trend by information technology [8]. The power plant has developed the fuel management subsystem in ERP, including fuel planning, procurement, transportation organization, management into the factory, management of the coal yard, coal blending, management into the furnace and performance evaluation, such as in Figure 6. The process of the data in the whole system is shown in Figure 7.

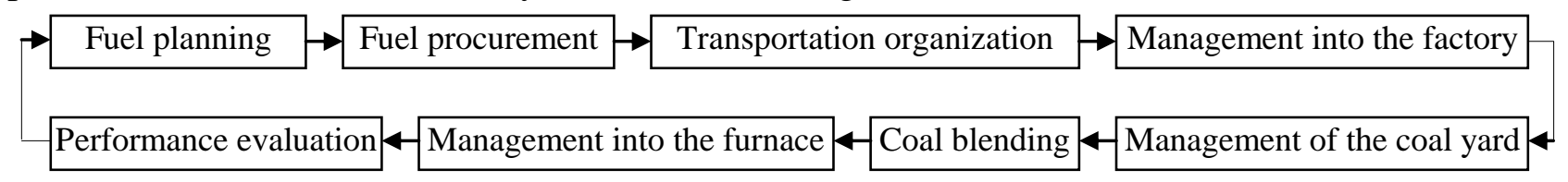

Fig. 6 Diagram of Function of the Fuel Management Subsystem in ERP

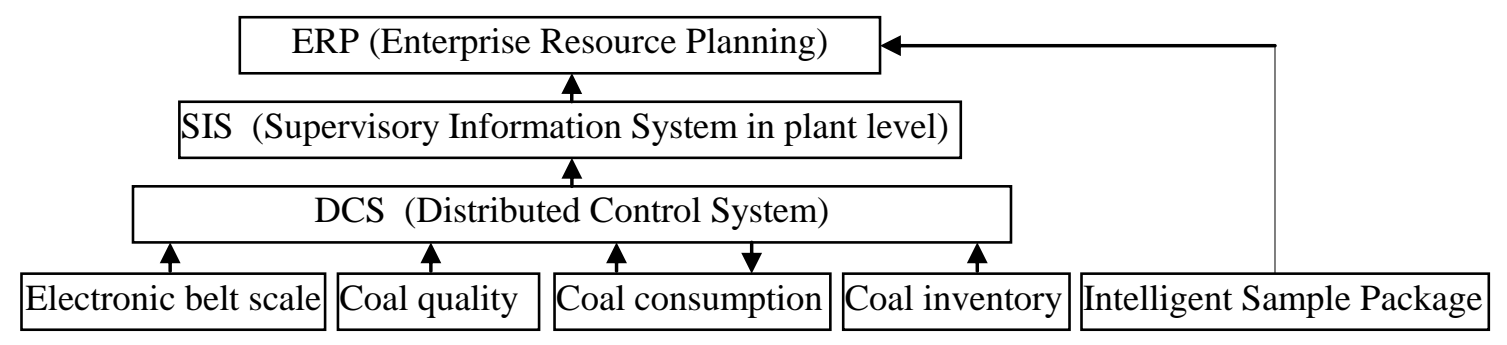

Fig. 7 Diagram of Data Flow in the Whole System

\section{Summary}

Thermal power plant is no longer a simple organization of production, but a profit-oriented modern enterprise. The lean production is based on professional institutions, intelligent equipment and information management. Coal management must abandon the traditional extensive mode, and make definite quantitative criteria applied to each link [9]. The enterprise can remain invincible in the fierce competition if the efficiency of power generation compares favourably with others [10].

\section{References}

[1] G.M.Liu, Analysis of the coal management strategy in thermal power plant, J. Science \& Technology Information. 28 (2013)139. (In Chinese)

[2] H.B.Xie, Elementary Analysis of the present situation and application of fuel management in thermal power plant, J. China Science and Technology Review. 35 (2014)240. (In Chinese)

[3] B.Wang, Strengthen the comprehensive supervision of fuel, J. China Power Enterprise Management. 8 (2010) 42-43. (In Chinese)

[4] Y.R.Li and H.Li: China Patent 21.2014 2 0002484.9. (2014). (In Chinese)

[5] C.W.Cao, Electric coal sampling technology and application, China Power Press. (In Chinese)

[6] Y.H.Li, The boiler system and its optimal operation in thermal power plant, China Power Press, 2011. (In Chinese)

[7] Information on http:// www.zjchec.com

[8] J.X.Liu, Discussion on effect of informatization on the social progress and the development of enterprises-Analysis of the trend of enterprise informatization, J. China Management Informationization. 17 (2014) 61-63. (In Chinese) 
[9] S.L.Yan and J.Y.Wang, The innovation of fuel management system in thermal power plant, J. China Power Enterprise Management. 8 (2007) 52-53. (In Chinese)

[10] J.Liu, The application of lean management in thermal power plant, J. China High Technology Enterprises. 36 (2010)105-107. (In Chinese) 